EESTI NSV TEADUSTE AKADEEMIA TOIMETISED 1954. III kd., nr. 1 ИЗВЕСТИЯ АКАДЕМИИ НАУК ЭСТОНСКОИ ССР 1954. ТоМ III, № 1

\title{
ИСПОЛЬЗОВАНИЕ СЛАНЦЕЗОЛЬНЫХ ВЯЖУЩИХ ДЛЯ БЕТОННЫХ И ЖЕЛЕЗОБЕТОННЫХ КОНСТРУКЦИЙ В СЕЛЬСКОХОЗЯЙТТЕННОМ СТРОИТЕЛЬСТВЕ
}

\author{
О. А. МАДДИСОН
}

действительный член Академии наук Эстонской ССР

Грандиозные задачи сельскохозяйственного строительства в нашей стране выдвигают необходимость широкого использования местных строительных материалов. В связи с этим особое внимание должно быть уделено местным строительным вяжущим, могущим заменить обыкновенный цемент в бетонных и железобетонных конструкциях * при применении их в многообразных условиях сельскохозяйственного строительства, как, например, при постройке в колхозах и совхозах жилых домов, животноводческих помещений и производственных зданий (коровников, свинарников, овчарен, теплиц, оранжерей, питомников и др.).

\section{1. Используемые сланцезольные вяжущие}

В настоящее время в Әстонской ССР, помимо обыкновенного цемента, намечается использование следующих двух основных видов сланцезольного вяжущего:

1) сланцезольное вяжущее под номенклатурным наименованием ку ке р м и т о бы к о в енн ы й **, представляющее собой тонкомолотую перевальную золу слоевого сжигания горючего сланца-кукерсита на колосниковых решетках парокотельных установок при температуре сжигания в пределах $900-1100^{\circ} \mathrm{C}$, и

2) сланцезольное вяжущее под номенклатурным наименованием к у керми т гд р а лически й**, представляющее собой также тонкомолотую золу, но только от сжигания сланца в пылевидном- состоянии в топках установок теплоэлектроцентрали в Қохтла-Ярве при температуре сжигания сланца $1250-1300^{\circ} \mathrm{C}$.

Кукермит обыкновенный, как низкомарочное сланцезольное вяжущее, нормативная прочность которого колеблется в пределах $25-50 \mathrm{kr} / \mathrm{cm}^{2}$,

* Вопрос о возможности замены обыкновенного цемента в строительстве Эстонской ССР местным строительным вяжущим, а также вопрос об условиях успешного применения местных сланцезольных вяжущих в бетоне и железобетоне разработан коллективом сотрудников Института стронтельства и строительных материалов АН ЭССР пол руководством автора в пределах первой наиболее трудоемкой и решающей стадии исследовательских работ.

** ТУ ЭССР 507-53.

*** TУ $Э$ ССР $508-53$. 
находит применение главным образом для изготовления кладочных и штукатурных растворов.

Для бетонных и железобетонных конструкций допустимо использование лишь кукермита гидравлического различных составов, обеспечивающих более высокие прочности. Постоянство изменения объема сланцезольного вяжущего при его твердении достигается добавлением к золе при ее заводском помоле активных гидравлических добавок в виде, например, трепела, некоторых видов обожженной глины - г л и н и т а, термически обработанного диатомита. Из названных добавок наиболее экономичным в условиях Эстонской ССР оказывается глинит, потребное количество которого составляет $30 \%$ от веса применяемого вяжущего. C добавкой глинита гидравлический кукермит представляет собой вяжущее под номенклатурным наименованием кукермит гидравлический улучшенный *.

Следует отметить, что прочность на сжатие улучшенного гидравлического кукермита, при испытаниях его в 28-дневном возрасте, не превышает вообще $250 \mathrm{kr} / \mathrm{cm}^{2}$; нормативная же его прочность колеблется в пределах $100-200 \mathrm{\kappa r} / \mathrm{cm}^{2}$.

Прочность сланцезольного вяжущего в $250 \mathrm{kr} / \mathrm{cm}^{2}$, вполне обеспечивающая изготовление бетона марок M-90 до M-110, является, однако, недостаточной для получения бетона более высоких марок, необходимого для бетонных и железобетонных конструкций в многообразных условиях сельскохозяйственного строительства. Для удовлетворения такой потребности приходится добавлять к основному сланцезольному вяжущему кукермиту гидравлическому улучшенному - некоторое количество обыкновенного цемента.

Сланцезольное вяжущее в виде улучшенного гидравлического кукермита с увеличением добавки к нему обыкновенного цемента өбразует с последним непрерывный ряд новых сланцезольных вяжущих с повышающимися техническими свойствами. Прочности получаемых при этом сланцезольных вяжущих могут быть исчислены на основании следующей экспериментально установленной зависимости:

$$
\mathrm{R}_{\mathrm{u}}=\mathrm{R}_{\mathrm{A}}+\left(\amalg-\mathrm{R}_{\mathrm{A}}\right) \cdot \frac{\mathrm{L}}{100} \cdot\left[1+\frac{2}{3}\left(1-\frac{\mathrm{L}}{100}\right)\right],
$$

где $\mathrm{R}_{\text {ц }}$ - марка (прочность на сжатие в 28-дневном возрасте) улучшенного гидравлического кукермита с добавкой «ц» процентов обыкновенного цемента марки Ц; RA - марка основного сланцезольного вяжущего улучшенного гидравлического кукермита.

Результаты стандартных испытаний сланцезольных вяжущих, с добавкой обыкновенного цемента и без такой добавки, показали, что сланцезольные вяжущие вполне пригодны для изготовления из них тяжелых (обычных) бетонов для бетонных и железобетонных конструкций (таблица 2).

\section{2. Применяемые марки тяжелого (обычного) сланцезольного бетона}

Для изготовления бетонных и железобетонных конструкций для сельскохозяйственного строительства в Эстонской ССР намечаются бетоны следующих общесоюзных стандартных марок (прочностей) (таблица 1).

* ту ЭССР 509-53. 


\begin{tabular}{l|c|c|c|c|c|c|c}
\hline Для бетонных работ & $M-50$ & $M-70$ & $M-90$ & $M-110$ & $M-140$ & $M-170$ & $M-200$ \\
\hline $\begin{array}{l}\text { Для железобетонных } \\
\text { конструкций }\end{array}$ & - & - & $M-90$ & $M-110$ & $M-140$ & $M-170$ & $M-200$ \\
\hline
\end{tabular}

Для получения достаточно плотного бетона марку вяжущего рекомендуется брать выше намечаемой марки бетона в определенных пределах. На основании долголетнего опыта бетонных работ эти пределы устанавливаются следующим образом: нижний предел марки сланцезольного вяжущего принимается обыкновенно равным удвоенной величине марки бетона, а верхний - примерно на $100 \mathrm{kr} / \mathrm{cm}^{2}$ выше нижнего.

Таблица 2

\begin{tabular}{|c|c|c|c|c|c|c|c|c|}
\hline \multicolumn{2}{|c|}{ Марки бетона } & \multirow{2}{*}{$\frac{M-50}{.100^{\alpha}}$} & \multirow{2}{*}{$\begin{array}{l}M-70 \\
n 150^{\alpha}\end{array}$} & \multirow{2}{*}{$\frac{M-90}{.200^{\alpha}}$} & \multirow{2}{*}{$\begin{array}{l}M-110 \\
.250^{\prime \prime}\end{array}$} & \multirow{2}{*}{$\frac{M-140}{, 300^{\alpha}}$} & \multirow{2}{*}{$\begin{array}{l}M-170 \\
{ }_{n} 350^{\alpha}\end{array}$} & \multirow{2}{*}{$\begin{array}{l}M-200 \\
\quad 400^{\alpha}\end{array}$} \\
\hline $\begin{array}{l}\text { Потребные } \\
\text { марки вя- }\end{array}$ & $\begin{array}{l}\text { Низшая } \\
\text { марка }\end{array}$ & & & & & & & \\
\hline & $\begin{array}{l}\text { Средняя } \\
\text { марка }\end{array}$ & $" 150^{\alpha}$ & $" 200^{\circ}$ & $" 250^{\prime \prime}$ & .300“ & $350 "$. & $400^{\alpha}$ & $450^{\circ}$ \\
\hline & $\begin{array}{l}\text { Высшая } \\
\text { марка }\end{array}$ & „200“ & $" 250 “$ & „300* & $.350^{\alpha}$ & $" 400 "$ & "450" & $.500^{*}$ \\
\hline \multicolumn{2}{|c|}{$\begin{array}{c}\text { Вид потребного } \\
\text { вяжущего }\end{array}$} & \multicolumn{2}{|c|}{$\begin{array}{l}\text { Улучшенный } \\
\text { гидравли- } \\
\text { ческий } \\
\text { кукермит }\end{array}$} & \multicolumn{4}{|c|}{$\begin{array}{c}\text { Улучшенный гидравлический ку- } \\
\text { кермит с добавкой обыкновенного } \\
\text { цемента }\end{array}$} & $\begin{array}{l}\text { Обыкно- } \\
\text { венный } \\
\text { цемент }\end{array}$ \\
\hline
\end{tabular}

П р и мечан и е. Количество обыкновенного цемента, которое необходимо добавить к улучшенному гидравлическому кукермиту с целью получения намечаемой марки бетона, может быть определено на осңовании зависимости (2).

В соответствии с реальными производственными возможностями изготовления в условиях Эстонской ССР основных вяжущих с достаточно высокой активностью, а именно: кукермита гидравлического улучшенного с активностыю «100» и выше и обыкновенного цемента марок до « $500 »$, в сельскохозяйственном строительстве республики в полной мере могут быть использованы предусмотренные для этого строительства марки бетона в пределах от $M-50$ до $M-200$, так как получение бетона марки M-50 обеспечивается средней активностью улучшенного гидравлического кукермита, равной «150». Для бетона марки $M-200$, изготовляемого на одном обыкновенном цементе, предельными значениями марок цемента будут « $400 »$ и «500».

При выборе вида и состава вяжущего для намечаемой марки бетона рекомендуется исходить из потребной средней величины марки вяжущего при заданных марках основных вяжущих - улучшенного гидравлического кукермита и обыкновенного цемента.

Количество обыкновенного цемента, которое необходимо добавить к улучшенному гидравлическому кукермиту с целью получения намеченной марки вяжущего, может быть ориентировочно определено на основании соответственно преобразованной зависимости (1):

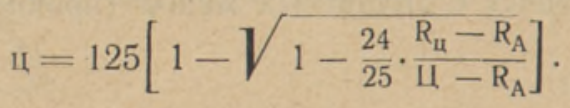




\section{3. Морозостойкость и водостойкость сланцезольного бетона}

Весьма существенным является вопрос о морозостойкости сланцезольного бетона. Учитывая условия службы такого бетона в сельскохозяйственном строительстве, испытание на морозостойкость образцов из обычного (тяжелого) бетона вполне возможно ограничить 15 циклами попеременного замораживания и оттаивания для бетона, находящегося в более или менее облегченных условиях службы, и 25 циклами для бетона, условия службы которого являются более жесткими.

Результаты проведенных испытаний на морозостойкость сланцезольных бетонов позволяют высказать следующее весьма существенное общее положение.

Бетон, изготовляемый на улучшенном гидравлическом кукермите с потребной для обеспечения намеченной его прочности добавкой $25-50 \%$ (по весу) обыкновенного цемента, выдерживает испытания на морозостойкость в указанных пределах вполне удовлетворительно.

Что же касается бетона, изготовляемого на улучшенном гидравлическом кукермите без добавки обыкновенного цемента, то такой бетон приходится пока считать неморозостойким и допускать его применение лишь в конструкциях, не подвергаемых замораживанию в насыщенном водой состоянин.

В отношении возможности повышения морозостойкости бетона нельзя не отметить, что такое повышение, принимая во внимание зависимость морозостойкости бетона в значительной мере от его водопоглощаемости и степени заполнения его пор, может быть достигнуто принятием мер, повышаюших водонепроницаемость бетона. Қ таким мерам относятся:

1. Выбор наиболее целесообразного гранулометрического состава смеси инертных компонентов (песка и щебня) бетона, обеспечивающего наибольшую возможную плотность бетона и вместе с тем повышенную его водонепроницаемость и, следовательно, и повышенную его морозостойкость.

2. Использование гидрофобизующей добавки к бетону в виде натрового мыла абиетиновой смолы (по ВНИИГ * в количестве $0,02 \%$ от веса сланцезольного вяжущего) с целью изменения обычной структуры бетонной массы с сообщающимися между собою порами в микроструктурную с разобщенными друг от друга микропорами, обладающую повышенной водонепроницаемостью и в связи с этим также повышенной морозостойкостью.

В отношении сопротивляемости сланцезольного бетона воздействию окружающей среды - в виде проточных пресных вод, жижы коровников и свинарников, влаги в кормовых силосных башнях, грунтовых вод с резко выраженной агрессивностью - можно с полным удовлетворением констатировать, что бетонные образцы, изготовленные на различных сланцезольных вяжущих как с добавкой гидрофобизующего натрового мыла абиетиновой смолы (по ВНИИГ в количестве $0,02 \%$ от веса вяжущего), так и без такой добавки, оказались после годичного непрерывного пребывания в условиях воздействия указанного многообразия факторов совершенно нетронутыми таким воздействием.

* Всесоюзный научно-исследовательский институт гидротехники. 


\section{4. Железобетонные конструкции на обычном (тяжелом) сланцезольном бетоне}

В случае использования сланцезольного вяжущего для изготовления бетона железобетонных конструкций возникают, помимо вопроса о прочности и стойкости бетона, еще следующие два существенных вопроса:

1) вопрос о степени сопротивления сдвигу так называемой гладкой арматуры в сланцезольном бетоне и

2) вопрос о стойкости (долговечности) изготовляемого на сланцезольном вяжущем железобетона в отношении возможной коррозии арматурной стали под воздействием сланцезольного вяжущего.

Результаты выполненных экспериментальных лабораторных исследований по определению сопротивления сдвигу арматуры в сланцезольных бетонах показали, что величина такого сопротивления вполне удовлетворительна.

Что касается вопроса о возможной коррозии арматурной стали под воздействием сланщезольного вяжущего, то при этом надо иметь в виду двоякого рода коррозию:

1) коррозию арматурной стали под влиянием содержащейся в золе горючего сланща активной сульфидной серы и

2) коррозию арматурной стали под влиянием окислительного процесса, вызываемого действием влажного воздуха, проникающего в толщу бетона и приходящего в соприкосновение с арматурной сталью, т. е. коррозию в виде простого ржавления арматуры.

Коррозия первого рода. Учитывая ничтожность $(0,15-$ $0,20 \%$ ) сульфидной серы, содержащейся в золе сжигания пылевидного горючего сланца, при высокощелочном характере сланцезольного вяжущего, выражающемся исключительно высоким значением кислотно-щелочной характеристики этого вяжущего $(\mathrm{pH}=12,60-12,70)$, нет основания опасаться сульфидной коррозии заделываемой в сланцезольный бетон стальной арматуры.

Коррозия в торого рода. Возникновение и развитие коррозии арматурной стали в виде ее ржавления под влиянием окислительного процесса, вызываемого действием проникающего к арматуре влажного воздуха, зависит от целого ряда факторов, в той или иной степени влияющих на интенсивность коррозионного состояния арматуры.

На основании трехмесячных наблюдений могут быть высказаны следующие положения.

1. Условия возникновения и развития процесса ржавления поверхности арматуры оказываются наиболее благоприятными в случае применения улучшенного гидравлического кукермита без добавки обыкновенного цемента. Ввиду этого следует пока воздержаться от применения указанного вяжущего для железобетона.

2. Возможность возникновения коррозии резко падает в случае добавки к улучшенному гидравлическому кукермиту обыкновенного цемента. Так, в случае добавки к указанному вяжущему, с целью повышения его прочности на сжатие, $25-50 \%$ по весу обыкновенного цемента картина коррозионного состояния арматуры оказывается вполне удовлетворительной.

3. Арматурная сталь с черной необработанной поверхностью, заделанная в сланцезольном растворе или бетоне, подвергается менее резкому коррозионному воздействию окружающей среды в виде раствора или бетона по сравнению с коррозионным воздействием среды в виде одного лишь теста вяжущего. Здесь сказывается смягчающее влияние инертных 
заполнителей (песка и щебня) на степень интенсивности проявления коррозии, обусловливаемой воздействием сланцезольного вяжущего.

4. Наиболее интенсивно проявляется коррозионный процесс на поверхности арматуры в случае пребывания железобетонного элемента во влажном воздухе (с относительной влажностью от 60 до 95\%). С наименьшей интенсивностью проявляется коррозия в случае пребывания железобетонного элемента в воде или в воздухе с относительной влажностью ниже $60 \%$.

5. Существенно снижается опасность возникновения коррозионного процесса в случае добавки к раствору и бетону гидрофобизующего натрового мыла абиетиновой смолы, содействующей улучшению микроструктуры бетонной массы в смысле уменьшения ее воздухо- и водопроницаемости и обеспечивающей этим сохранность арматуры от ржавления.

Исходя из доказанного экспериментальным путем положения, что возникновение и развитие коррозионного процесса ржавления арматурной стали происходит под влиянием проникающего к поверхности арматуры влажного воздуха, меры предотвращения возникновения и развития такого процесса заключаются в создании препятствий проникновению влажного воздуха к поверхности арматуры через толщу сланцезольной массы бетона. Поэтому все, что в той или иной форме может служить средством создания препятствий проникновению влажного воздуха в толщу бетона, будет реальной мерой предотвращения коррозионного процесса арматурной стали в железобетоне.

К числу таких мер предотвращения относятся:

а) выбор наиболее целесообразного гранулометрического состава смеси инертных компонентов (песка, гравия и щебня) с целью достижения наибольшей возможной плотности бетона;

б) изменение обычной структуры бетонной массы с сообщающимися между собою порами в микроструктурную с разобщенными друг от друга микропорами путем добавления к бетону натрового мыла абиетнновой смолы- (по ВНИИГ в количестве $0,02 \%$ от веса вяжущего);

в) добавка к улучшенному гидравлическому кукермиту обыкновенного цемента.

Все сказанное относится к сланцезольному железобетону в случае твердения бетона в нормальных условиях температурно-влажностного режима. Картина коррозионного состояния арматуры существенно меняется в случае твердения железобетона в условиях пропаривания.

\section{5. Пропариваемые железобетонные строительные детали на сланцезоль- ных вяжущих}

Применение метода пропаривания в пропарочных камерах имеет пелью ускоренное индустриальное изготовление бетонных и железобетонных строительных деталей в связи с монтажным-методом возведения построек.

В отношении пропариваемого железобетона представляется необходимым исследовать ряд принципиальных вопросов, обусловливаемых специњнкой сланцезольного вяжущего.

К числу таких вопросов относятся:

1) прочность пропариваемого бетона в зависимости от вида сланцезольного вяжушего, продолжительности и режима пропаривания и воз. раста бетона после пропаривания; 
2) коррозионное состояние арматурной стали в пропаренном сланцезольном железобетоне.

Қак общий результат пропаривания бетона, изготовляемого на сланцезольных вяжущих, следует отметить, что получаемые прочности пропариваемого сланцезольного бетона являются, в случае пропаривания бетона в течение 40 часов при температуре $80^{\circ} \mathrm{C}$, во всех отношениях удовлетворительными.

Что же касается коррозионного состояния арматурной стали в пропариваемом сланцезольном железобетоне, то крайне характерно, что коррозионный процесс на поверхности арматурной стали оказывается более интенсивным, чем при обычном твердении бетона в нормальных условиях температурно-влажностного режима. Такая повышенная интенсивность коррозионного состояния проявляется, однако, не сразу после пропаривания бетона, а по прошествии некоторого более или менее продолжительного промежутка времени (одного месяца и более). Не менее характерно и то обстоятельство, что меры предотвращения развития коррозионного процесса арматурной стали, рекомендуемые в отношении сланцезольного железобетона, твердеющего в нормальных условиях температурно-влажностного режима, оказываются малоэффективными в отношении пропариваемого сланцезольного железобетона.

В связи с изложенным немаловажное значение в рассматриваемом случае имеет, без сомнения, величина кислотно-щелочной характеристики $\mathrm{pH}$ и структура сланцезольной бетонной среды, окружающей арматуру.

Коррозионный процесс арматуры при значении величины pH около 9,5 находится как бы в неустойчивом состоянии в отношении дальнейшего направления процесса и представляет собой в некотором роде границу двух областей с отличающимися друг от друга особенностями характера проявляющихся коррозионных явлений. * При значениях $\mathrm{pH}<9,5$ беспрепятственно имеет место процесс коррозии - ржавление арматуры. При значениях же $\mathrm{pH}>9,5$ на поверхности арматуры образуется более устойчивая защитная пленка гидрата закиси железа и в связи с этим коррозионный процесс, имевший место при значениях $\mathrm{pH}<9,5$, прекращается. Этому содействует также заметное понижение растворимости закиси железа.

Исходя из положения, что возникновение и развитие коррозионного процесса ржавления арматуры в железобетоне находится в непосредственной связи с влиянием проникающего через толщу бетона к поверхности арматуры влажного воздуха (кислорода) при соответственном значении величины $\mathrm{pH}$, меры предотвращения коррозионного прощесса или дальнейшего развития такового заключаются, очевидно, в создании пре пятствий возможному проникновению к поверхности арматуры влажного воздуха (кислорода), а также в одновременном создании в массе теста, раствора или бетона, как в среде, окружающей арматуру, неблагоприятных условий для возникновения и дальнейшего развития коррозионного процесса, другими словами, в созданни среды с $\mathrm{pH}>9,5$.

В связи с этим заслуживают особого внимания результаты некоторых экспериментальных исследований, свидетельствующие о том, что значе ние величины рН твердеющего в условиях пропаривания сланцезольного теста может измениться в продолжение процесса твердения. ** Этим вы-

* См. Г. В. А ки мов, Основы учения о коррозии и защите металлов, Металлург издат, 1946, стр. 372 , фиг. 293. Растворимость закиси железа в зависимости от рН.

** Эти результаты получены аспирантом Института строительства и строительных материалов АН ЭССР X. Х. Корровищем. 
ражается чрезвычайно важное положение, относящееся к тесту, твердеющему в условиях пропаривания.

В таблице 3 приведены сравнительные значения величины $\mathrm{pH}$, относящиеся как к использованным сланцезольным вяжущим, так и к изготовленному из них и затвердевшему в пропарочной камере тесту.

Таблица 3

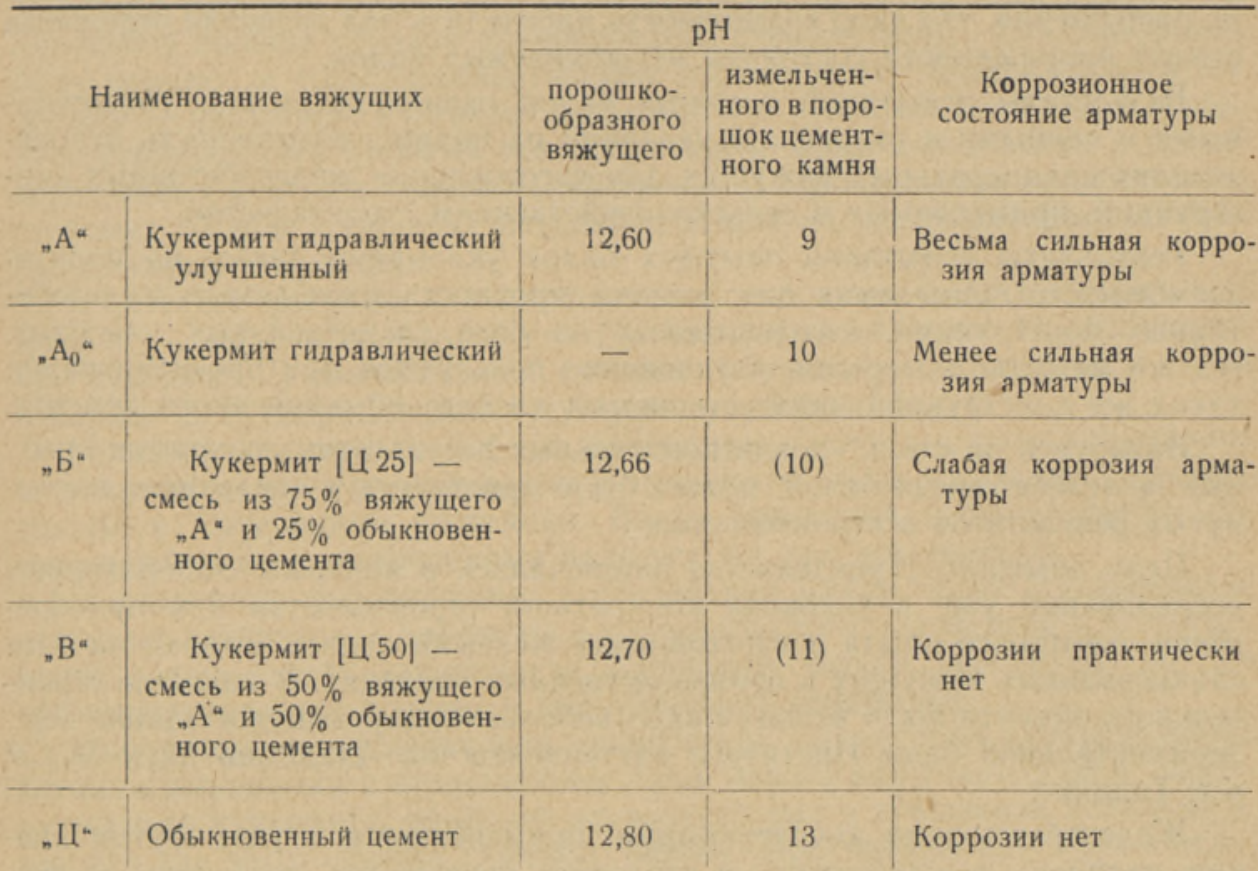

Пр и меч а н ие. Значения $\mathrm{pH}$, приведенные в скобках, исчислены применительно к значениям $\mathrm{pH}$, соответствующим порошкообразному вяжущему.

Из данных, приведенных в таблице 3 , не трудно усмотреть почти полное совпадение значений величины $\mathrm{pH}$ для обыкновенного цемента в порошкообразном состоянии $(\mathrm{pH}=12,80)$ и для измельченного в порошок затвердевшего теста того же обыкновенного цемента $(\mathrm{pH}=13)$. В отношении же сланцезольного вяжущего вида «А» и « $\mathrm{A}_{0}$ » заметна ощутительная разница в сторону снижения значений величины $\mathrm{pH}$ для цементного камня указанных сланцезольных вяжущих. Значения величины $\mathrm{pH}$ измельченного в порошок цементного камня этих вяжущих находятся в зоне, опасной в отношении вероятного возникновения или возобновления коррозионного процесса арматуры. Действительное коррозионное состояние арматуры подтверждает высказанное положение.

\section{6. Применение сланцезольного бетона в железобетонных конструкциях в строительной практике}

Возможность широкого применения сланцезольного бетона в железобетонных конструкциях потребовала еще убедительных доказательств в отношении 1) удовлетворительной совместной работы бетона и арматуры и 2) возможности применения для расчета прочности сланцезольных же- 
лезобетонных конструкций тех же методов и тех же расчетных формул, которые установлены общесоюзными стандартами и нормами для железобетонных конструкций, изготовляемых на обыкновенном цементе.

Принимая во внимание, что в случае железобетона совместная работа бетона и арматуры проявляется нанболее рельефно при изгибе, для получения необходимых доказательств была изготовлена на сланцезольных вяжущих серия железобетонных балок, испытанных на изгиб вплоть до их разрушения, что дало возможность проследить ход развития отдельных стадий напряженного состояния испытываемых балок.

Результаты испытаний опытных балок оказались весьма убедительными и ценными в отношении указаний на полную возможность использования сланцезольных вяжущих для изготовления железобетонных конструкций, применяемых в сельскохозяйственном строительстве.

Результаты испытания опытных балок указывают также на полную возможность применения для расчета прочности изгибаемых железобетонных конструкций, изготовляемых на базе сланцезольных вяжущих, тех же методов, которыми обыкновенно пользуются при проектировании таких же конструкций, осуществляемых на базе обыкновенного цемента.

Базируясь на столь удовлетворительных-результатах испытания опытных железобетонных балок, можно было приступить к внедрению достигнутых результатов в строительство.

Цель опытного строительства заключалась в контроле лабораторных исследований уже в условиях конкретного строительства и в приобретении некоторого опыта в изготовлении железобетонных деталей на базе сланцезольных вяжущих в производственных условиях. В качестве строительного объекта было использовано небольшое двухэтажное здание Экспериментальной базы Института растениеводства Академии наук ЭССР в г. Таллине.

Железобетонными конструкциями, примененными в упомянутом здании, являлись междуэтажное и чердачное перекрытия, состоящие из железобетонных балок и плит, а также некоторые оконные и дверные перемычки.

Балки и плиты изготовлялись в производственных условиях на Таллинском заводе силикатного кирпича «Силикат». Транспорт балок и плит, а равно монтаж их на месте работ не причинили им никаких повреждений, несмотря на то, что детали поднимались на месте работ вручную (без крана).

Испытание несущей способности перекрытий здания Экспериментальной базы конкретной нагрузкой (кирпичами), соответствовавшей расчетной полезной нагрузке, с определением прогибов дало вполне удовлетворительные результаты. Так, испытание железобетонной балки, изготовленной на улучшенном гидравлическом кукермите с добавкой $50 \%$ обыкновенного цемента, показало, что прогиб этой балки, нагруженной полезной нагрузкой в $240 \mathrm{kr} / \mathrm{M}$, составлял после 16-часового пребывания нагрузки на балке всего лишь $\frac{1}{2500}$ пролета при теоретическом значении прогиба около $\frac{1}{1500} *$.

* В отношении применения сланцезольного бетона в сельскохозяйственном стронтельстве можно указать на бетонные работы (по устройству пола и яслей коровника), выполненные под руководством старшего преподдавателя Таллинского политехнического института В. Х. Кикаса в совхозе жПенинги», вблизи г. Таллина, где было уложено 80 м $^{3}$ сланцезольного бетона. 


\section{7. Пенобетон на сланцезольном вяжущем}

В заключение следует указать на возможность применения в сельскохозяйственном строительстве в условиях Эстонской ССР сланцезольного пенобетона.

Современное ускоренное строительство основано на применении более или менее крупных блоков и сборных деталей перекрытий.

Ввиду того, что в условиях Эстонской ССР обыкновенный цемент, являющийся вообще основой пенобетонного строительства, успешно может быть заменен в сельскохозяйственном стронтельстве сланцезольным вяжущим - неизбежно возникает потребность в использовании для ускоренного строительства типовых жилых домов и животноводческих и производственных построек сельскохозяйственного строительства пенобетонных стеновых блоков и сборных деталей перекрытий, изготовляемых на базе сланцезольных вяжущих.

В качестве вяжущих для изготовления пенобетона и строительных элементов - деталей из него могли бы быть использованы: 1) обыкновенный кукермит, 2) обыкновенный кукермит улучшенный, 3) гидравлический кукермит и 4) гидравлический кукермит улучшенный.

Прекрасные результаты были достигнуты также в случае применения в качестве вяжущего натуральной немолотой золы сжигания горючего сланца в пылевидном состоянии. Ввиду некоторой неоднородности натуральной золы с обобщениями надо все же еще повременить.

Проведенные лабораторные исследования имели целью установление основных технических параметров сланцезольного пенобетона и в особенности установление зависимости прочности такого пенобетона от его объемного веса, его состава и водовяжущего отношения.

Лабораторные исследования технических параметров сланцезольного бетона проводились с применением лишь одного вяжущего в виде гидравлического кукермита, наиболее изученного уже в отношении использования его для изготовления тяжелого бетона. Получаемые при этом в отношении пенобетона результаты проверялись затем в условиях применения их к другим сланцезольным вяжущим, с целью получения общей картины применимости сланцезольных вяжущих для изготовления пенобетонных стронтельных деталей вообще.

Для проведения предварительных лабораторных исследований был взят песчаный заполнитель в виде дезинтегрированного кварцевого песка Таллинского завода силикатного кирпича «Кварц» с удельной поверхностью не менее $600 \mathrm{~cm}^{2} / \mathrm{r}$.

В качестве пенообразователя, необходимого для изготовления пенобетона, был использован клее-канифольный пенообразователь.

Исследования технических свойств сланщезольного пенобетона охватывали составы его с весовыми отношениями сланцезольного вяжущего и песчаного заполнителя: $1: 0 ; 1: 0,5 ; 1: 1$ и $1: 2$.

Пронаривание сланцезольных пенобетонных образцов проводилось в лабораторной пропарочной установке завода «Кварц».

Результаты лабораторных исследований показывают, что в случае продолжительности пропаривания в 20 часов при температуре $80^{\circ} \mathrm{C}$ сланцезольный пенобетон обладает достаточной прочностью (от 5 до $50 \mathrm{kr} / \mathrm{cm}^{2}$ ) при вполне удовлетворительном объемном весе (в пределах 0,6-1,0 т/. $\mathrm{m}^{3}$ ). Такой материал вполне пригоден для изготовления, например, стеновых блоков для сельскохозяйственных построек.

Повышение прочности пенобетона легко может быть достигнуто путем увеличения продолжительности пропаривания, например, до 40 часов с сохранением прежнего объемного веса. 
Одновременно с лабораторными исследованиями по установлению главных параметров пенобетона были проведены исследования с целью выяснения возможности использования уже достигнутых результатов для изготовления пенобетонных строительных деталей сначала в полупроизводственных, а затем и в производственных условиях - на заводе силикатного кирпича «Силикат».

Для опытного внедрения достигнутых результатов лабораторных исследований с применением гидравлического кукермита были использованы некоторые из указанных выше сланцезольных вяжущих, намеченных для изготовления пенобетона и строительных деталей из них, а именно: кукермит обыкновенный, кукермит обыкновенный улучшенный, кукермит гидравлический и натуральная зола сжигания горючего сланца в пылевидном состоянии.

Из указанных сланцезольных вяжущих изготовлялись крупные стеновые пенобетонные блоки размерами $1,25 \times 1,20 \times 0,35$ метра, офактурен- ные с одной стороны. Все блоки изготовлялись состава 1 : 0 , т. е. из одного лишь вяжущего, без добавки мелкого дезинтегрированного кварщевого песка.

Прогревание изготовленных пенобетонных блоков производилось на специальном стенде, устроенном по инициативе сектора строительства Института строительства и строительных материалов на заводе силикатного кирпича «Силикат». Основной стенд, предназначенный главным образом для изготовления стеновых блоков, представляет собой горизонтальную бетонную площадку размерами 4 ×8 метров. В толще бетона заложена сеть труб, разбитая на пять секций, по которым циркулирует пар, нагревающий бетонную площадку стенда вместе с расположенными на ней отлитыми в формах пенобетонными деталями (в виде блоков и других элементов строящегося здания). Прогревательная установка стенда допускает как использование отдельных секций, так и использование их в различной комбинации в зависимости от расположения на стенде отдельных форм для изготовления деталей.

Все расположенные на стенде формы перекрываются общим в пределах всего стенда утепленным деревянным коробом со съемной по частям крышей, образующим на стенде над формами специальную паровую рубашку. Пар, прошедший по трубам стенда, направляется специальными шлангами в паровую рубашку (в пространство над формами). Әтим создается над формами с отлитыми в них деталями некоторое подобие дополнительной пропарочной камеры, содействующей более равномерному распределению температуры в толще находящихся на стенде пенобетонных деталей. Температура в теле блоков измерялась термопарами.

Параллельно с пенобетонными деталями прогревались в тех же температурно-влажностных условиях также контрольные образцы - кубы, предназначенные для установления прочности получаемого пенобетона. Кроме прогреваемых на стенде контрольных кубов, для проверки действительной прочности получаемого пенобетона из отдельных изготовленных блоков выпиливались дополнительные контрольные кубы. Прогревание блоков и контрольных кубов на стенде продолжалось в среднем 40 часов при температуре $80^{\circ} \mathrm{C}$.

Результаты испытаний контрольных образцов показали вполне удовлетворительные прочности и объемные веса прогреваемых на стенде пенобетонных блоков.

Вполне удовлетворительными оказались также результаты испытания пенобетонных образцов на морозостойкость, выдержавших 15-кратное попеременное их замораживание и оттаивание. Это является весьма ценным достижением. 
Тем не менее надо признать, что изготовление сланцезольных пенобетонных деталей, как дело совершенно новое, требует еще дальнейшего изучения и приобретения необходимого практического навыка.

Вместе с тем необходимо отметить, что в связи с удовлетворительными, в общем, результатами, достигнутыми в отношении использования для изготовления пенобетонных стеновых блоков сланцезольных вяжущих, Институтом строительства и строительных материалов было представлено на выставке строительной техники (состоявшейся 6 сентября 1953 г. на Певческом поле в Таллине по случаю Дня строителей г. Таллина) несколько пенобетонных стеновых блоков на обыкновенном кукермите отмеченных выше размеров $(1,25 \times 1,20 \times 0,35$ м) с офактуренной наружной и ровной, натурального вида пенобетонной внутренней поверхностью. Кроме того, на выставке были представлены некоторые железобетонные стойки и карнизные блоки.

\section{8. Общее заключение}

На достигнутые до настоящего времени хотя и заметные успехи как в области исследований основных свойств сланцезольных вяжущих, так и в отношении применения указанных вяжущих для изготовления тяжелого (обычного) бетона и железобетона, а также для изготовления пенобетона - можно и должно смотреть как на результаты лишь первой фазы исследований в этой области, нуждающиеся еще в дальнейшем их расширении и углублении.

В первую очередь нуждаются в дальнейшем углубленном изучении методы термической обработки сланцезольных железобетонных деталей с одновременным всесторонним освещением физико-химической стороны вопроса о возникновении и дальнейшем развитии коррозии арматурной стали как во время процесса термической обработки железобетонных деталей, так в особенности после таковой.

Дальнейшего улучшения требует, кроме того, изготовление пенобетонных деталей, являющихся в связи с широким развитием сельскохозяйственного строительства одним из основных материалов для этого строительства. 